\title{
Adsorption of Nanoceria by Phosphocholine Liposomes
}

\author{
Yibo Liu and Juewen Liu* \\ Department of Chemistry, Waterloo Institute for Nanotechnology, University of Waterloo, \\ Waterloo, Ontario, N2L 3G1, Canada \\ Email: liujw@uwaterloo.ca
}




\begin{abstract}
Nanoceria $\left(\mathrm{CeO}_{2}\right.$ nanoparticle $)$ possesses a number of enzyme-like activities. In particular, it scavenges reactive oxygen species (ROS) leading in vitro and in vivo anti-oxidation studies. An important aspect of fundamental physical understanding is its interaction with lipid membranes, the man component of the cell membrane. In this work, adsorption of nanoceria onto phosphocholine (PC) liposomes was performed. PC lipids are the main constituent of the cell outer membrane. Using fluorescence quenching assay, nanoceria adsorption isotherm was determined at various $\mathrm{pH}$ 's and ionic strengths. A non-Langmuir isotherm occurred at $\mathrm{pH} 4.0$ due to lateral electrostatic repulsion among adsorbed cationic nanoceria. The phosphate group in the PC lipid is mainly responsible for the interaction, and adsorbed nanoceria can be displaced by free inorganic phosphate. The tendency of the system to form large aggregates is a function of $\mathrm{pH}$ and the concentration of nanoceria, attributable to nanoceria being positively charged at $\mathrm{pH} 4$ and neural at physiological $\mathrm{pH}$. Calcein leakage test indicates that nanoceria induces liposome leakage due to transient lipid phase transition, and cryo-TEM indicates that the overall shape of the liposome is retained although deformation is still observed. This study provides fundamental biointerfacial information at a molecular level regarding the interaction of nanoceria and model cell membranes.
\end{abstract}




\section{Introduction}

$\mathrm{CeO}_{2}$ nanoparticles (NP) or nanoceria are an important material as catalysts, gas sensors, UV filters, and solid oxide fuel cells. ${ }^{1}$ Its unique properties are attributed to the surface $\mathrm{Ce}^{3+}$ ions, providing a redox couple with $\mathrm{Ce}^{4+} .2,3$ The $\mathrm{Ce}^{3+}$ sites are accompanied by oxygen vacancies near the surface. Therefore, small $\mathrm{CeO}_{2} \mathrm{NPs}$ of several nanometers possess enhanced activities due to a large surface-to-volume ratio. ${ }^{4-6}$

With high biocompatibility, nanoceria is also an attractive material for various biological applications. ${ }^{2,4}$ For example, it was reported that nanoceria can scavenge reactive oxygen species (ROS) in living systems with superoxide dismutase and catalase-like activities. ${ }^{2,7-9}$ In a few cases, nanoceria protected cells from oxidative stress induced by ROS or radiation. ${ }^{10-14}$ It was also reported that nanoceria protects normal cells but not cancer cells. ${ }^{15}$ On the other hand, $\mathrm{CeO}_{2}$ nanorods with a high aspect ratio had pro-inflammatory effects. ${ }^{16}$ In vivo studies revealed that nanoceria fights against inflammation, ischemic stroke and radiation-induced damages. ${ }^{11,17}$ With so many biological applications, however, few studies touched upon its interaction with biological molecules, ${ }^{18}$ especially biomembranes. ${ }^{10,16}$

To enter cells, nanoceria has to first cross the cell membrane. Therefore, it is important to study its interaction with membranes. ${ }^{19-21}$ The main components of the cell membrane are lipids with phosphocholine (PC) lipids being the most abundant on the outer membrane of eukaryotic cells. The interactions of PC membranes with various nanomaterials have been studied, ${ }^{21-26}$ in particular, with various oxides. ${ }^{27-30}$ A primary example is the spontaneous fusion of PC liposomes onto silica forming supported bilayers using van der Waals force. ${ }^{31-33}$ In contrast, PC liposomes adsorb onto $\mathrm{TiO}_{2}$ NPs via a stronger force, likely bonding with the lipid phosphate group. ${ }^{27-29,34,35}$ Most of the metal oxide NPs studied so far have a size of several tens of 
nanometer or larger. Compared to them, an interesting feature of nanoceria is its small size, which may exert a different behavior. For example, very small silica NPs behave completely different when mixed with PC liposomes compared to the larger ones. ${ }^{36}$ While larger nanoceria can also be made, small particles (below $10 \mathrm{~nm}$ ) are required for catalytic activity and

biomedical relevance. ${ }^{4-6}$ In this work, we explore the interaction between nanoceria of $\sim 5 \mathrm{~nm}$ and PC liposomes in terms of adsorption, stability, and membrane integrity.

\section{Materials and Methods}

Chemicals. All the phospholipids were purchased from Avanti Polar Lipids (Alabaster, AL). $\mathrm{CeO}_{2}$ dispersion (catalog number: 289744, $20 \%$ dispersed in $2.5 \%$ acetic acid), disodium calcein, and Triton X-100 were from Sigma Aldrich. 4-(2-hydroxyetyl)-1piperazineethanesulfonic acid (HEPES), acetate, phosphate and sodium chloride were from Mandel Scientific (Guelph, ON, Canada). Milli-Q water was used to prepared all the buffers and suspensions.

Preparation of liposomes. Liposomes were prepared using the standard extrusion method through a $100 \mathrm{~nm}$ membrane as described previously. ${ }^{27}$ DOPC (1,2-dioleoyl-sn-glycero-3phosphocholine) and DPPC (1,2-dipalmitoyl-sn-glycero-3-phosphocholine) with a total mass of $2.5 \mathrm{mg}$ were respectively dissolved in chloroform. For $\mathrm{Rh}$ (rhodamine)-labeled liposome, $1 \%$ Rh-PE (2-dioleoyl-sn-glycero-3-phosphoethanolamine-N-(lissaminerhodamine B sulfonyl) (ammonium salt) was included. After evaporating chloroform, the dried lipid films were stored at $-20{ }^{\circ} \mathrm{C}$ under a $\mathrm{N}_{2}$ atmosphere prior to use. To prepare liposomes, the lipid films were hydrated with $0.5 \mathrm{~mL}$ buffer (10 mM HEPES, $100 \mathrm{mM} \mathrm{NaCl}, \mathrm{pH}$ 7.6) to reach a lipid concentration of 5 $\mathrm{mg} \mathrm{mL} \mathrm{m}^{-1}$. For DPPC liposome, the lipids films were hydrated at $60{ }^{\circ} \mathrm{C}$ for $2 \mathrm{~h}$ and were extruded at $60{ }^{\circ} \mathrm{C}$. To encapsulate calcein, the lipid films were hydrated with $100 \mathrm{mM}$ calcein overnight 
followed by extrusion for 21 times. Free calcein was removed by passing $35 \mu \mathrm{L}$ of the samples through a PD-10 column using $25 \mathrm{mM}$ HEPES for elution. The first $600 \mu \mathrm{L}$ of the fluorescent fraction was collected.

$\zeta$-potential and dynamic light scattering (DLS). The $\zeta$-potential of $\mathrm{CeO}_{2} \mathrm{NPs}\left(100 \mu \mathrm{g} \mathrm{mL}^{-1}\right)$ was measured at various pH's in water on a Malvern Zetasizer NanoZS90 with a He-Ne laser $(633 \mathrm{~nm})$ at $90^{\circ}$ collecting optics. $\mathrm{HCl}$ and $\mathrm{NaOH}$ were used to adjust $\mathrm{pH}$. The size was measured with $\mathrm{CeO}_{2}\left(1 \mathrm{mg} \mathrm{mL}^{-1}\right.$, in $25 \mathrm{mM}$ acetate buffer, $\mathrm{pH}$ 4) and with DOPC liposomes (100 $\mu \mathrm{g} \mathrm{mL}^{-1}$ in $25 \mathrm{mM}$ HEPES buffer, $\mathrm{pH}$ 7.6).

Liposome adsorption studied by fluorescence quenching. $\mathrm{A} \mathrm{CeO}_{2}$ suspension was gradually titrated into the Rh-liposome $\left(50 \mu \mathrm{g} \mathrm{mL} \mathrm{L}^{-1}, 1 \mathrm{~mL}\right)$ in buffer $(25 \mathrm{mM}$ acetate, $\mathrm{pH} \mathrm{4}$, or $25 \mathrm{mM}$ acetate with $150 \mathrm{mM} \mathrm{NaCl}$, or $25 \mathrm{mM}$ HEPES, $\mathrm{pH}$ 7.6). $\mathrm{CeO}_{2}$ stock solutions (1 or $10 \mathrm{mg} \mathrm{mL}^{-1}$ ) were used for this titration. The fluorescence spectra were recorded using a Varian Eclipse fluorometer (Ex: $560 \mathrm{~nm}$; Em: $592 \mathrm{~nm})$.

Phosphate inhibition studies. $\mathrm{CeO}_{2} \mathrm{NPs}\left(10 \mathrm{mg} \mathrm{mL}^{-1}\right)$ were first incubated in phosphate buffer $(100 \mathrm{mM})$ for $30 \mathrm{~min}$ to cap the surface with phosphate. Then, 5 or $10 \mu \mathrm{L}$ above mixture was added to Rh-labeled liposomes $\left(25 \mu \mathrm{g} \mathrm{mL} \mathrm{mL}^{-1}, 1 \mathrm{~mL}\right)$ and the fluorescence was measured. To study displacement, to $1 \mathrm{~mL}$ Rh-labeled liposome $\left(25 \mu \mathrm{g} \mathrm{mL} \mathrm{m}^{-1}\right), \mathrm{CeO}_{2} \mathrm{NPs}$ were added. Afterwards, 20 $\mu \mathrm{L}$ phosphate buffer $(500 \mathrm{mM}, \mathrm{pH} 7.6$ or $\mathrm{pH} 4)$ was added and the fluorescence was measured.

Complex stability test. To a Rh-labeled liposome $\left(50 \mu \mathrm{g} \mathrm{mL} \mathrm{m}^{-1}, 200 \mu \mathrm{L}\right)$ in buffer $(25 \mathrm{mM}$ acetate, $\mathrm{pH} 4$ or $25 \mathrm{mM}$ HEPES, $\mathrm{pH}$ 7.6), a small amount of $\mathrm{CeO}_{2}$ was added to reach a final concentration of $1,2,5,10,25,50,100$, or $200 \mu \mathrm{g} \mathrm{mL}{ }^{-1}$. After 30 min incubation, the mixture was centrifuged at $10,000 \mathrm{rpm}$ for $10 \mathrm{~min}$ to collect the supernatant. The supernatant was diluted 
10 times and its fluorescence was measured. To re-disperse the $\mathrm{DOPC} / \mathrm{CeO}_{2}$, the complex was prepared in HEPES buffer ( $25 \mathrm{mM}, \mathrm{pH} 7.6)$ as above and centrifuged at 10,000 rpm for $10 \mathrm{~min}$. The pellets were collected and re-dispersed in $200 \mu \mathrm{L}$ acetate buffer $(50 \mathrm{mM}, \mathrm{pH} 4)$. After sonication, the suspension was again centrifuged, the supernatant was collected and diluted 10 times for fluorescence measurement. In another case, the complexes were prepared in acetate buffer $(25 \mathrm{mM}, \mathrm{pH}$ 4). After $30 \mathrm{~min}$ incubation, $150 \mathrm{mM} \mathrm{NaCl}$ was added to destabilize the $\mathrm{DOPC} / \mathrm{CeO}_{2}$ complexes. After centrifugation at $10,000 \mathrm{rpm}$ for $10 \mathrm{~min}$, the pellets were collected and re-dispersed in $200 \mu \mathrm{L}$ HEPES ( $50 \mathrm{mM}$, pH 7.6) by sonication. These sample were again centrifuged at 10,000 rpm for $10 \mathrm{~min}$, the supernatant was collected and diluted 10 times for fluorescence measurement.

Liposome leakage studies. To monitor $\mathrm{CeO}_{2} \mathrm{NP}$ induced liposome leakage, $3 \mu \mathrm{L}$ of the above purified calcein-loaded liposomes were added to $597 \mu \mathrm{L}$ HEPES buffer $(25 \mathrm{mM}$, pH 7.6$)$ in a quartz cuvette at room temperature. The background fluorescence was monitored for $5 \mathrm{~min}$ before adding various amount of $\mathrm{CeO}_{2} \mathrm{NPs}$ (e.g. 10 or $20 \mu \mathrm{L}$ of $1 \mathrm{mg} \mathrm{mL}^{-1} \mathrm{CeO}_{2}$, or $5 \mu \mathrm{L}$ of 10 $\mathrm{mg} \mathrm{mL} \mathrm{m}^{-1} \mathrm{CeO}_{2}$ ). The fluorescence was monitored for another 20 min followed by adding $20 \mu \mathrm{L}$ phosphate buffer (500 mM, pH 7.6). At $25 \mathrm{~min}, 10 \mu \mathrm{L}$ of 5\% Triton X-100 was added. Calcein was excited at $485 \mathrm{~nm}$, and the emission was monitored at $525 \mathrm{~nm}$.

Transmission electron microscopy (TEM) and Cryo-TEM. TEM measurements were performed on a Philips CM10 transmission electron microscope. A $10 \mu \mathrm{L} \mathrm{CeO}_{2}$ solution was spotted on a 230 mesh holy carbon copper grid and extra solution on the grid was removed by filter paper. The sample was dried in air before measurement. Cryo-TEM sample was prepared by mixing DOPC liposomes $\left(50 \mu \mathrm{g} \mathrm{mL}^{-1}\right)$ and $\mathrm{CeO}_{2}\left(50 \mu \mathrm{g} \mathrm{mL} \mathrm{m}^{-1}\right)$ in acetate buffer $(25 \mathrm{mM}, \mathrm{pH}$ 4). A $5 \mu \mathrm{L}$ sample was spotted on a plasma treated carbon coated copper TEM grid. The gird was 
blotted with two pieces of filter paper for $2 \mathrm{sec}$ and quickly plunged into liquid ethane. The sample was then loaded to a liquid $\mathrm{N}_{2}$ cooled cold stage imaged with a $200 \mathrm{kV}$ field emission TEM (FEI Tecnai G2 F20) at $-175^{\circ} \mathrm{C}$.

Differential scanning calorimetry (DSC). To measure the phase transition temperature $\left(T_{\mathrm{c}}\right)$, DPPC liposomes $\left(100 \mu \mathrm{g} \mathrm{mL}^{-1}\right)$ and $\mathrm{DPPC} / \mathrm{CeO}_{2}$ (mass ratio of $1: 1$ and 1:5) were used. The samples were degassed prior to injection into the DSC sample cell, while the reference cell was filled with the corresponding buffer. Each sample was scanned from 25 to $65{ }^{\circ} \mathrm{C}$ with a rate of $1{ }^{\circ} \mathrm{C} \min ^{-1}$ using a VP-DSC instrument (MicroCal). Six scans were carried out for each sample and the fifth scan was plotted.

\section{Results and Discussion}

Characterization of nanoceria and liposomes. DLS characterization based on scattering intensity shows our $\mathrm{CeO}_{2} \mathrm{NPs}$ have an average hydrodynamic size of $20 \mathrm{~nm}$, while the numberbased size distribution is centered at $\sim 5 \mathrm{~nm}$ (Figure 1a). It is known that light scattering strongly favors larger particles, and our data suggest that this nanoceria sample is slightly aggregated. Although many previous work prepared nanoceria capped by various ligands and polymers to

facilitate dispersion, ${ }^{14,37,38}$ we are interested in understanding the native surface property. As a result, our nanoceria did not have a strong capping ligand, explaining the moderate aggregation. A TEM micrograph shows the size of individual nanoceria is below $5 \mathrm{~nm}$ and some aggregates can be also observed (Figure 1a inset), which is consistent with the DLS data. Its crystallinity was confirmed by high-resolution TEM (HRTEM) (Figure 1b). Such small particles were used to ensure high catalytic activity. ${ }^{4-6}$ 
Next, we studied the surface charge of nanoceria with a careful $\mathrm{pH}$ titration. At $\mathrm{pH}$ lower than 7 , nanoceria is positively charged, while the surface becomes negative at higher $\mathrm{pH}$ (Figure 1c). Therefore, at physiological $\mathrm{pH}$, nanoceria is nearly charge neutral, which may affect its colloidal stability due to a lack of charge stabilization.
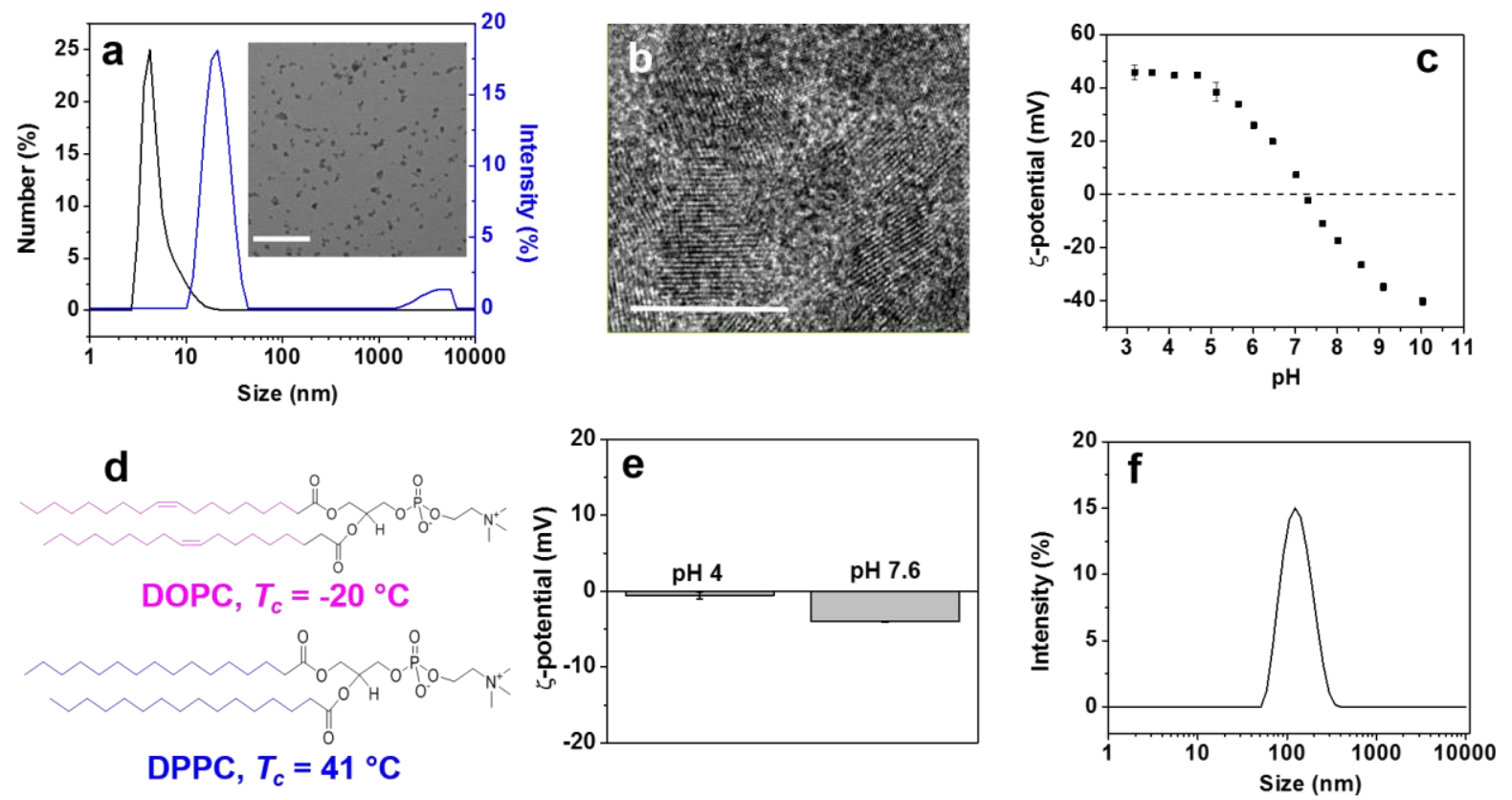

Figure 1. (a) DLS spectra of $\mathrm{CeO}_{2} \mathrm{NPs}$ dispersed in $25 \mathrm{mM}$ acetate (pH 4) with both number and scattering intensity based distribution. Inset: a TEM micrograph of the sample (scale bar: $100 \mathrm{~nm}$ ). (b) A HRTEM micrograph of $\mathrm{CeO}_{2}$ NPs showing its crystalline structure (scale bar: 10 $\mathrm{nm}$ ). (c) $\zeta$-potential of $\mathrm{CeO}_{2} \mathrm{NPs}$ as a function of $\mathrm{pH}$. (d) The structures of DOPC and DPPC lipids, and their phase transition temperature $\left(T_{\mathrm{c}}\right)$ values are labeled. (e) $\zeta$-potential of DOPC liposomes in $25 \mathrm{mM}$ acetate (pH 4) and HEPES (pH 7.6) buffers. (f) DLS spectrum of the DOPC liposomes in $25 \mathrm{mM}$ HEPES (pH 7.6). 
The structure of a DOPC lipid is shown in Figure 1d. Its headgroup contains a negatively charged phosphate and a positively charged choline. Therefore, this zwitterionic PC lipid is overall charge neutral, which is confirmed by $\zeta$-potential measurement (Figure 1e). The neutral charge avoids electrostatic interactions with nanoceria. Based on our previous studies, the lipid phosphate group is likely to be important for interaction with nanoceria. ${ }^{27-30}$ Our liposomes were prepared using the standard extrusion method through $100 \mathrm{~nm}$ pores, which is consistent with the DLS measurement of $\sim 120 \mathrm{~nm}$ (Figure 1f).

Nanoceria is adsorbed by DOPC liposomes. To study their interaction, we first measured nanoceria adsorption by DOPC liposomes containing $1 \%$ rhodamine $(\mathrm{Rh})$ label. To this liposome sample, we gradually titrated $\mathrm{CeO}_{2} \mathrm{NPs}$ at $\mathrm{pH} 4$ and $\mathrm{pH} 7.6$, respectively. We chose these two $\mathrm{pH}$ values since the catalytic activity of $\mathrm{CeO}_{2}$ is the highest at $\mathrm{pH} 4,{ }^{39}$ while $\mathrm{pH} 7.6$ is the physiological condition.

The fluorescence spectra of the Rh-labeled DOPC liposomes at different nanoceria concentrations are shown in Figure 2a, and an overall trend of fluorescence decrease is observed. We measured the UV-Vis spectra of our nanoceria and its mixture with DOPC liposome at $\mathrm{pH} 4$ (Figure S1a), where no light scattering feature was observed. In addition, no light absorption was observed beyond $400 \mathrm{~nm}$. Therefore, the drop of fluorescence cannot be explained by light scattering or the inner-filter effect. Nanoceria is a strong quencher for many adsorbed fluorophores. ${ }^{40}$ Without light scattering, we attribute the fluorescence drop here to the adsorption of nanoceria by the liposome, directly quenching the associated $\mathrm{Rh}$ fluorophore.

The amount of quenching was quantified by plotting the relative fluorescence change $\left(\Delta F / F_{0}\right)$ at each $\mathrm{CeO}_{2}$ concentration. At $\mathrm{pH} 4$, the fluorescence initially dropped quickly. 
With $>20 \mu \mathrm{g} \mathrm{mL}^{-1}$ of $\mathrm{CeO}_{2}$, however, little further quenching was observed (Figure $2 \mathrm{~b}$, green trace). Even with $500 \mu \mathrm{g} \mathrm{mL}^{-1}$ of $\mathrm{CeO}_{2}$, quenching only reached $\sim 30 \%$. Therefore, the surface of DOPC liposomes was not fully occupied by $\mathrm{CeO}_{2}$ at $\mathrm{pH} 4 . \mathrm{CeO}_{2} \mathrm{NPs}$ are positively charged at $\mathrm{pH} 4$ (Figure 1C). The initially adsorbed $\mathrm{CeO}_{2}$ may electrostatically repel further incoming NPs. To confirm this hypothesis, we then repeated the measurement in the presence of $150 \mathrm{mM} \mathrm{NaCl}$ to screen charge interactions (no $\mathrm{NaCl}$ was included in the previous experiment). In this case, we indeed observed stronger quenching reaching 50\% (Figure 2b, red trace). This indicates that more $\mathrm{CeO}_{2} \mathrm{NPs}$ were adsorbed by screening the charge repulsion. The incomplete quenching can be explained by that only around $50 \%$ of the Rh-labels were on the outer leaflet of the bilayer, while the labels in the inner leaflet were not quenched by $\mathrm{CeO}_{2}$. This also suggests that $\mathrm{CeO}_{2}$ although small in size, did not penetrate through the bilayer membrane.
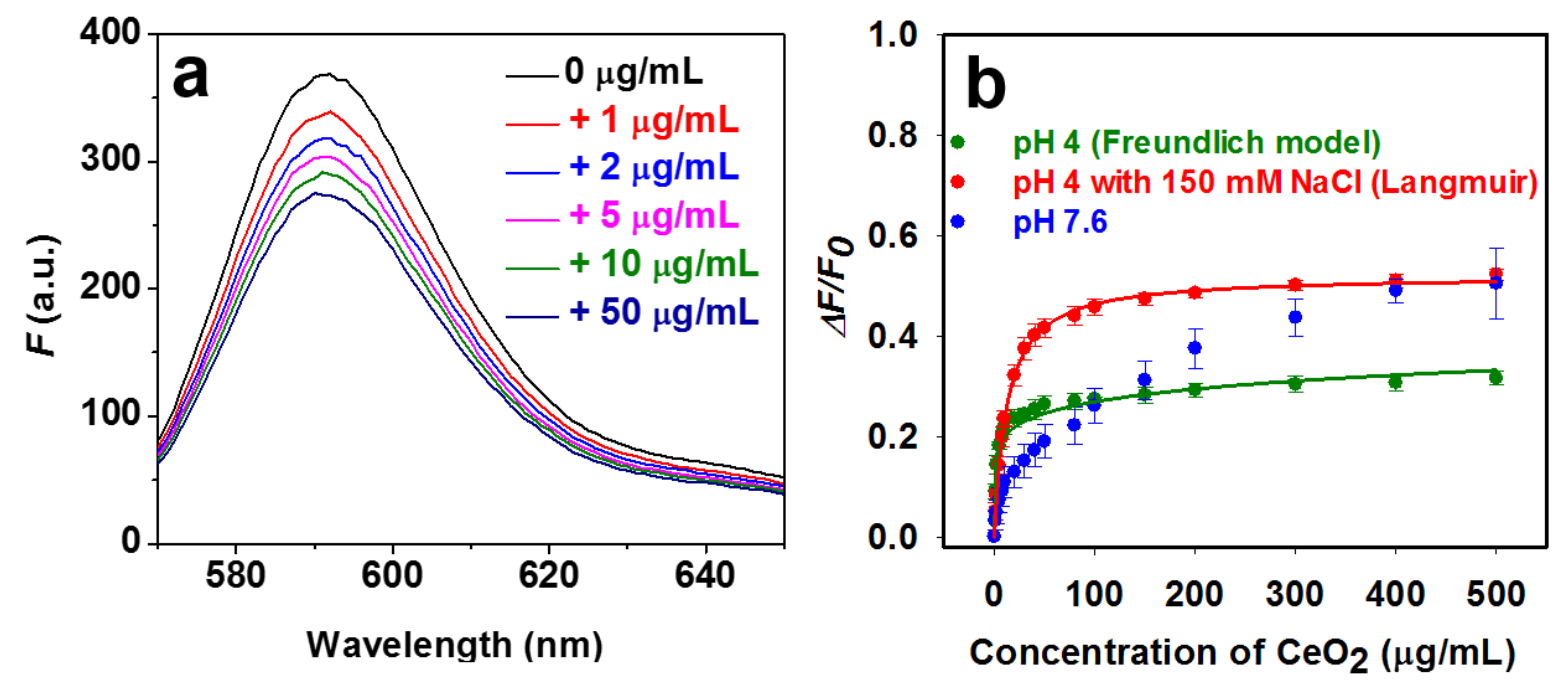

Figure 2. (a) Fluorescence spectra of the Rh-labeled DOPC liposomes at different $\mathrm{CeO}_{2}$ concentrations dispersed in $25 \mathrm{mM}$ acetate, $\mathrm{pH}$ 4. (b) Adsorption isotherms of $\mathrm{CeO}_{2} \mathrm{NPs}_{\text {s }}$ onto 50 $\mu \mathrm{g} \mathrm{mL}^{-1} \mathrm{Rh}$-labeled DOPC liposomes at $\mathrm{pH} 4$ without $\mathrm{NaCl}$ (green), with $150 \mathrm{mM} \mathrm{NaCl}$ (red), and at $\mathrm{pH} 7.6$ without $\mathrm{NaCl}$ (blue). 
The $\mathrm{pH} 4$ plots in Figure $2 \mathrm{~b}$ are essentially adsorption isotherms. For quantitative analysis, we fitted the data. At $\mathrm{pH} 4$ without $\mathrm{NaCl}$, a simple Langmuir isotherm failed to account for the data. The cationic $\mathrm{CeO}_{2} \mathrm{NPs}$ repel each other at $\mathrm{pH} 4$, which conflicts with a basic assumption of Langmuir isotherm that adsorbed molecules do not interact. Thus, we fitted the data with the Freundlich isotherm $y=0.1478 x^{0.13}$ (Figure $2 \mathrm{~b}$ green trace), which takes into consideration lateral repulsion. On the other hand, adsorption at $\mathrm{pH} 4$ with $150 \mathrm{mM} \mathrm{NaCl}$ was nicely fitted using the Langmuir isotherm model, because lateral electrostatic interactions were screened. Based on this fitting, a dissociation constant $\left(K_{\mathrm{d}}\right)$ of $12.4 \mu \mathrm{g} \mathrm{mL}-1 \mathrm{CeO}_{2}$ and a final quenching of $52 \%$ at full surface coverage are obtained.

On the other hand, at $\mathrm{pH} 7.6$, the initial stage of quenching was milder, but the final quencher reached $>50 \%$ (Figure $2 \mathrm{~b}$, blue trace). The UV-Vis spectra of both $\mathrm{CeO}_{2}$ and its mixture with DOPC liposome showed a quite obvious light scattering effect due to aggregation of the involved particles (Figure S1b). As such, not all the decreased fluorescence is attributable to direct fluorescence quenching since light scattering can also contribute. Forming large aggregates is quite common in liposome/NP systems. ${ }^{41-43}$ This complication made it difficult for quantitative data fitting, and the higher fluorescence drop beyond $50 \%$ at high $\mathrm{CeO}_{2}$ concentrations might be a pure result of light scattering as the surface might have already been saturated. It is interesting to note that at $\mathrm{pH}$ 7.6, an initial high quenching efficiency was observed. At low $\mathrm{CeO}_{2}$ concentrations, the light scattering effect is small, and this initial quenching is then supportive of $\mathrm{CeO}_{2}$ adsorption. No fitting of this data set was performed due to the light scattering effect.

Lipid phosphate based adsorption. Since cerium is a hard metal that has a strong affinity to phosphate, ${ }^{40,44,45}$ we propose that the phosphate group in the lipid might be playing a critical 
role. To test this, we added free inorganic phosphate ions to the $\mathrm{CeO}_{2} \mathrm{NPs}$ prior to mixing them with DOPC (Figure 3a). In this case, free phosphate inhibited nanoceria adsorption at both $\mathrm{pH} 4$ and 7.6. This supports the affinity between nanoceria and phosphate. Since adding phosphate has also increased the ionic strength of the solution, we also did a control experiment with 10-fold more $\mathrm{NaCl}$ added (Figure S2). In this case, efficient adsorption still occurred, confirming the specific role of phosphate. To further test this mechanism, we mixed DOPC and $\mathrm{CeO}_{2}$ first, followed by adding phosphate to see if phosphate can displace $\mathrm{CeO}_{2}$ (Figure 3b). Fluorescence was recovered at both $\mathrm{pH}$ 's, indicating that the displacement reaction indeed occurred, also supporting $\mathrm{CeO}_{2}$ interacting with phosphate group in the PC lipid.
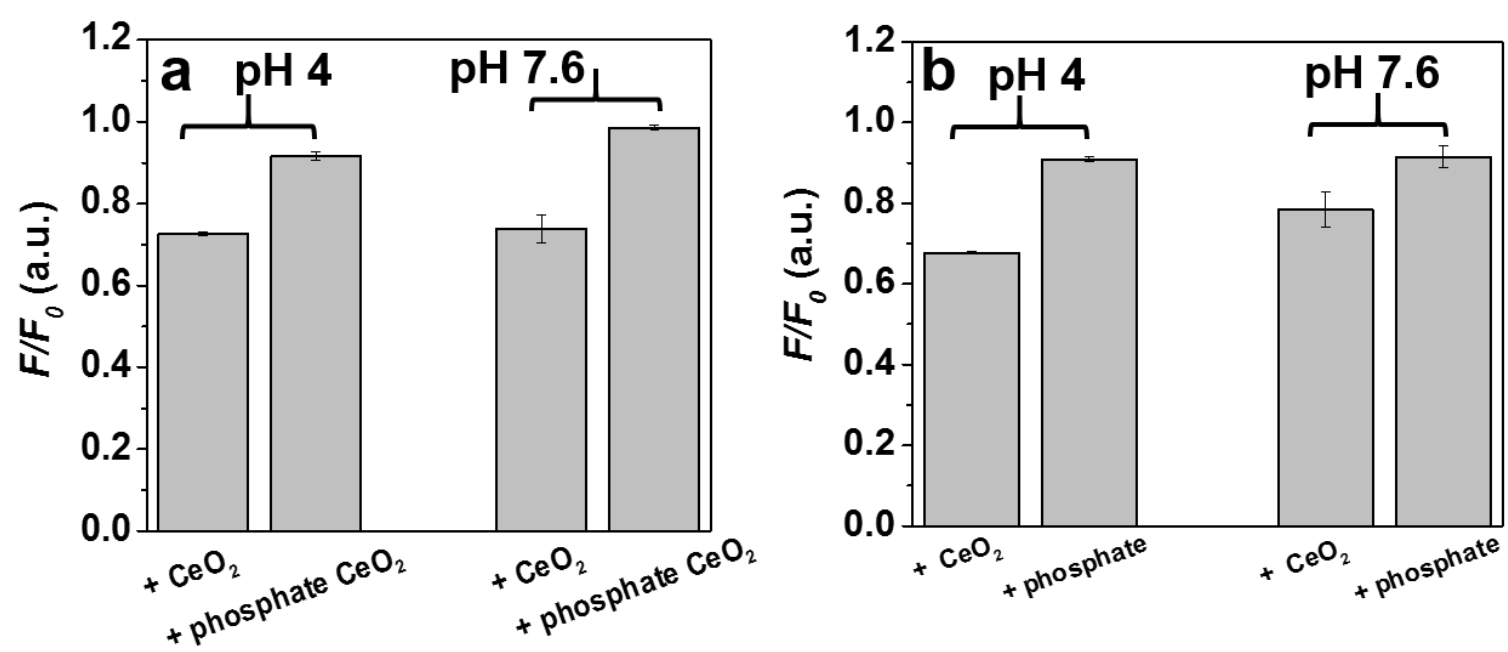

Figure 3. (a) Phosphate inhibited $\mathrm{CeO}_{2}$ adsorption on the Rh-labeled DOPC liposomes $(25 \mu \mathrm{g}$ $\left.\mathrm{mL}^{-1}\right)$ at $\mathrm{pH} 4$ and $\mathrm{pH}$ 7.6. (b) Phosphate $(10 \mathrm{mM})$ induced the $\mathrm{CeO}_{2}$ desorption at $\mathrm{pH} 4$ and $\mathrm{pH}$ 7.6. 
Aggregation and re-stabilization of the adsorption complex. After confirming the adsorption of nanoceria by the liposomes, we next studied the further aggregation of this system. Since nanoceria may bridge a few liposomes, the system might grow into large aggregates. In this experiment, Rh-labeled liposomes were incubated with various concentrations of $\mathrm{CeO}_{2}$. Then the mixture was centrifuged at 10,000 rpm for $10 \mathrm{~min}$ and the supernatant fluorescence intensity was measured. Free liposomes cannot be precipitated at this condition (Figure S3), allowing us to distinguish between well-dispersed liposomes and extensively aggregated structures. At pH 4, the supernatant fluorescence gradually decreased with increasing $\mathrm{CeO}_{2}$ (Figure 4a, pink bars). The lowest fluorescence was achieved at a $\mathrm{CeO}_{2}$ NPs concentration of $10 \mu \mathrm{g} \mathrm{mL}^{-1}$. Under this condition, the precipitated liposome reached the maximal value. As the concentration of $\mathrm{CeO}_{2}$ NPs was further increased, fluorescence started to increase again in the supernatant, suggesting liposome re-stabilization by $\mathrm{CeO}_{2}$ NPs. This may be attributed to that at $\mathrm{CeO}_{2}$ concentration lower than $10 \mu \mathrm{g} \mathrm{mL}^{-1}$, the nanoparticles could bridge the liposomes to form aggregates with decreased stability. With more $\mathrm{CeO}_{2}$ added, the bridging phenomenon was disrupted, and the whole liposome surface become positive charged due to the adsorption of $\mathrm{CeO}_{2} \mathrm{NPs}$. Both contribute to the re-stabilization. At $\mathrm{pH} 7.6$, however, no such re-stabilization was observed (Figure 4a, blue bars) since $\mathrm{CeO}_{2} \mathrm{NPs}$ are charge neutral at this $\mathrm{pH}$, and there is no driving force for the bridges to be disrupted.

We also quantitatively measured the size and $\zeta$-potential change when adding various amount of nanoceria to DOPC liposomes at $\mathrm{pH} 4$ (Figure 4d-f). The size initially increased with the $\mathrm{CeO}_{2}$ concentration up to $25 \mu \mathrm{g} \mathrm{mL} \mathrm{m}^{-1}$, while further increase of $\mathrm{CeO}_{2}$ has made the size smaller (Figure 4d). It is interesting to note that the largest size was still below $200 \mathrm{~nm}$, suggesting that this system did not aggregate extensively at $\mathrm{pH} 4$. With more than $100 \mu \mathrm{g} \mathrm{mL}^{-1}$ 
of $\mathrm{CeO}_{2}$, another peak just above $10 \mathrm{~nm}$ was observed, attributable to the free $\mathrm{CeO}_{2} \mathrm{NPs}$ (Figure 4e). The $\zeta$-potential gradually increases with increasing $\mathrm{CeO}_{2}$ concentration and reaches a plateau at $25 \mu \mathrm{g} \mathrm{mL} \mathrm{m}^{-1}$ (Figure $4 \mathrm{f}$ ). This suggests that beyond this moment, all the measured surfaces were $\mathrm{CeO}_{2}$, either as free NPs or adsorbed on the liposome.
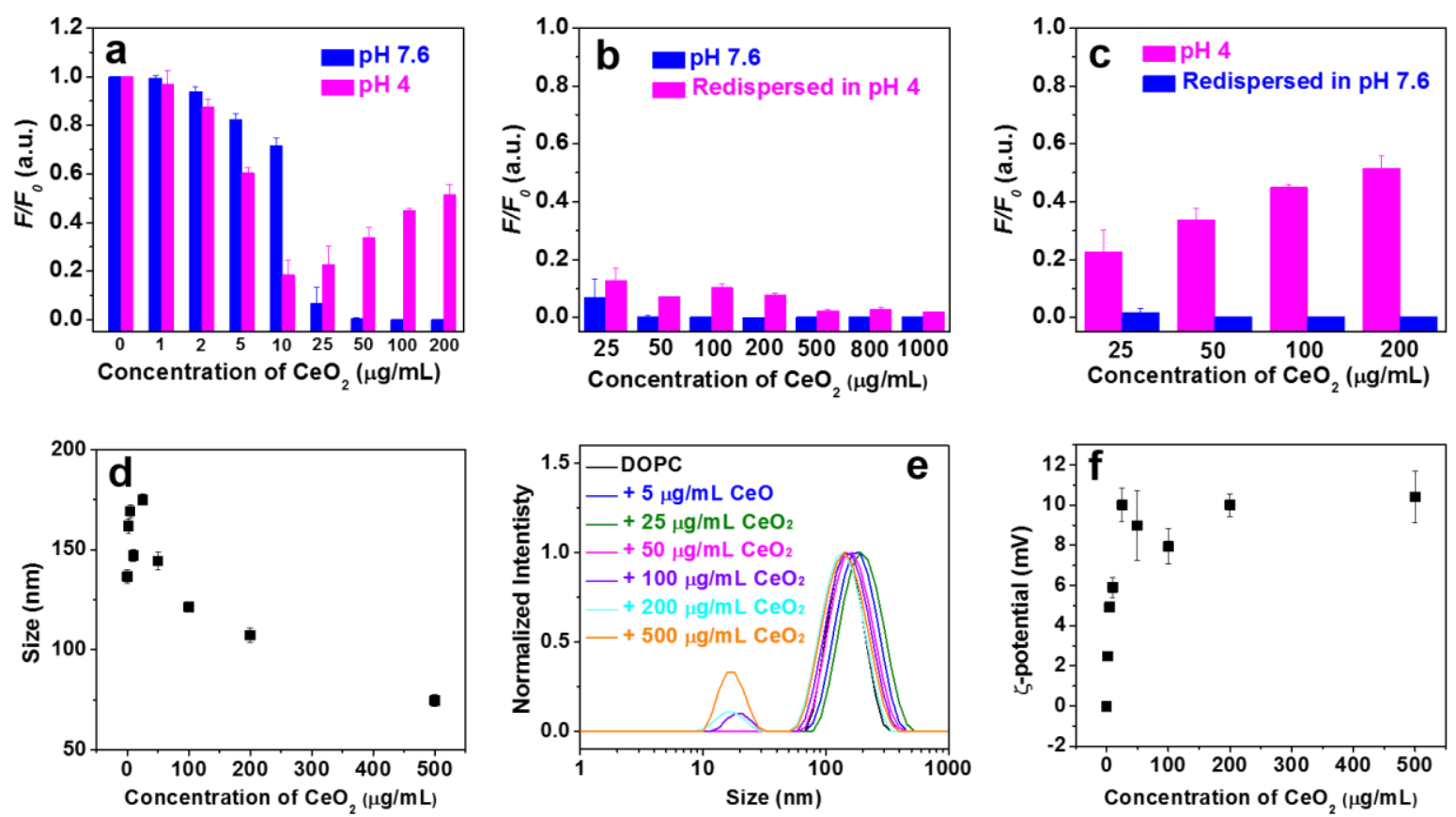

Figure 4. (a) Fluorescence of the supernatant after mixing $\mathrm{CeO}_{2}$ and $\mathrm{Rh}-\mathrm{DOPC}$ at $\mathrm{pH} 4$ and $\mathrm{pH}$ 7.6 and then centrifugation. A finally increased fluorescence at $\mathrm{pH} 4$ suggests re-stabilization of this system. (b) The complex prepared at $\mathrm{pH} 7.6$ and re-dispersed at $\mathrm{pH} 4$ failed to show restabilization. (c) The complex prepared at $\mathrm{pH} 4$ and re-dispersed at $\mathrm{pH}$ 7.6. (d) Averaged hydrodynamic size of $\mathrm{DOPC} / \mathrm{CeO}_{2}$ complexes as a function of $\mathrm{CeO}_{2}$ concentration at $\mathrm{pH} 4$. (e) DLS spectra of DOPC/CeO 2 complexes with different $\mathrm{CeO}_{2}$ amount at $\mathrm{pH} 4$. (f) $\zeta$-potential of DOPC/CeO $\mathrm{C}_{2}$ complexes as a function of $\mathrm{CeO}_{2}$ concentration at $\mathrm{pH} 4$. 
In addition, when $\mathrm{CeO}_{2}$ and DOPC were first mixed at $\mathrm{pH} 7.6$ and then re-dispersed at $\mathrm{pH} 4$, much less supernatant fluorescence was observed compared to those prepared at $\mathrm{pH} 4$ directly (Figure $4 \mathrm{~b}$ ). This suggests that the majority of complexes formed at $\mathrm{pH} 7.6$ were stably crosslinked by $\mathrm{CeO}_{2}$ NPs. In comparison, when the $\mathrm{CeO}_{2} / \mathrm{DOPC}$ complexes were prepared at $\mathrm{pH}$ 4 and re-dispersed at $\mathrm{pH} 7.6$, no fluorescence was observed in the supernatant (Figure 4c). This indicates that the complexes were readily aggregated at $\mathrm{pH} 7.6$, attributable to the lack of charge on the $\mathrm{CeO}_{2} \mathrm{NPs}$ at this $\mathrm{pH}$.

Based on the above understanding, we proposed an interaction model. At $\mathrm{pH} 4$, both the DOPC liposome and $\mathrm{CeO}_{2} \mathrm{NPs}$ are well dispersed in solution. At low $\mathrm{CeO}_{2}$ concentrations, $\mathrm{CeO}_{2}$ NPs moderately crosslink the liposomes, resulting in a small aggregates $(<200 \mathrm{~nm})$ that can be precipitate by centrifugation. With further increasing $\mathrm{CeO}_{2} \mathrm{NPs}$, each liposome surface is densely covered by $\mathrm{CeO}_{2}$ and the crosslinkers are disrupted, leading to re-stabilization (Scheme 1a). At $\mathrm{pH}$ 7.6, $\mathrm{CeO}_{2}$ aggregation happened even in the absence of DOPC. Upon mixing, immediate crosslinking is formed by aggregated $\mathrm{CeO}_{2} \mathrm{NPs}$ and they remained aggregate even by adjusting the $\mathrm{pH}$ to 4 (Scheme $1 \mathrm{~b}$ ). 

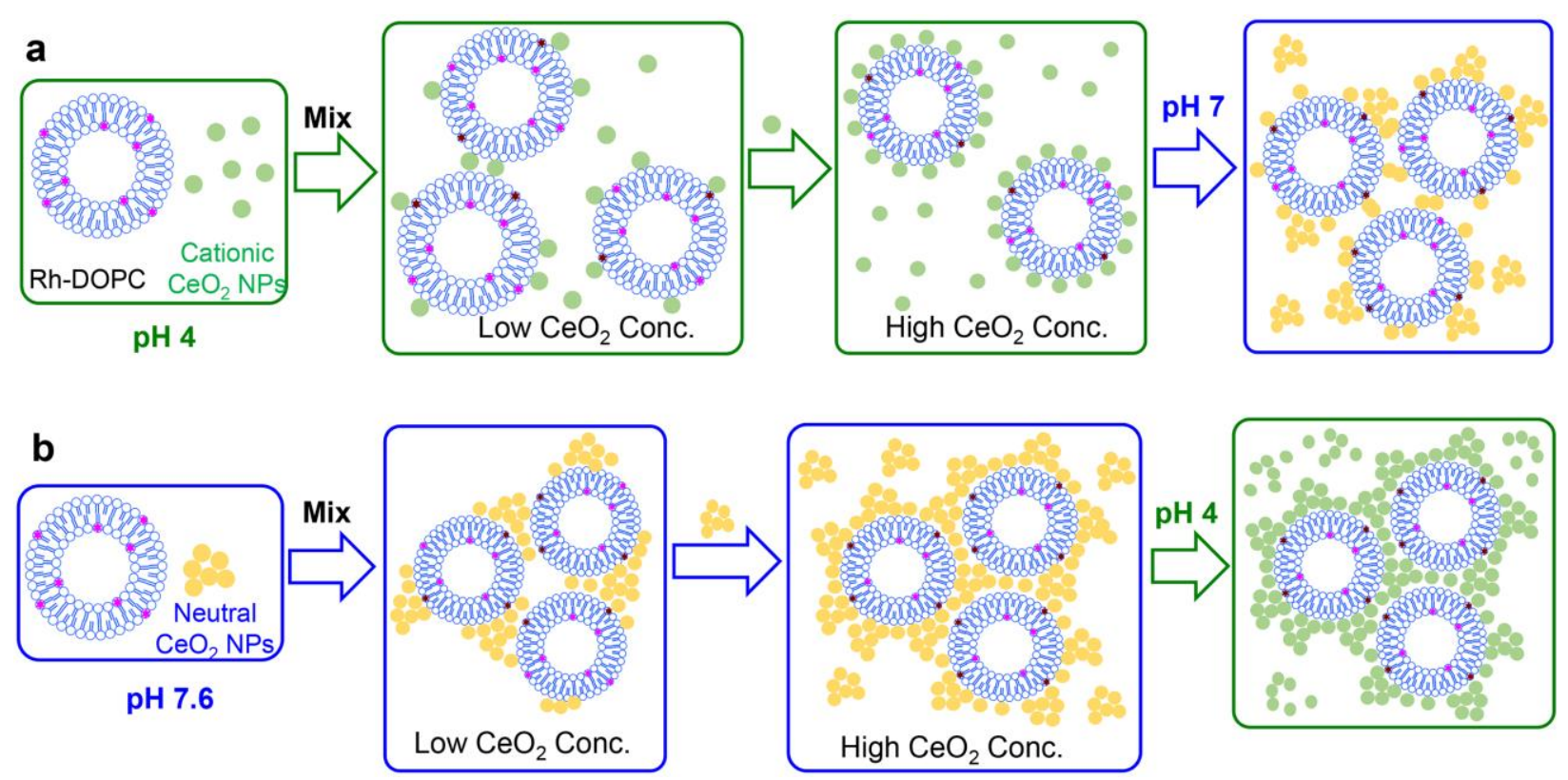

Scheme 1. Schematic illustration of adsorption of DOPC and $\mathrm{CeO}_{2}$ at (a) $\mathrm{pH} 4$ and (b) $\mathrm{pH}$ 7.6. At $\mathrm{pH} 4$, there is a re-dispersion of the system by adding more $\mathrm{CeO}_{2} \mathrm{NPs}$ due to charge repulsion. At $\mathrm{pH}$ 7.6, $\mathrm{CeO}_{2}$ NPs are nearly charge neutral, and are readily aggregated. The aggregates can further bridge liposomes to form even larger aggregates.

Nanoceria induces liposome leakage. A key question regarding nanoparticle/membrane interaction is membrane integrity, which can be probed by a leakage assay. In this work, 100 $\mathrm{mM}$ calcein was encapsulated in each DOPC liposome and most of the free calcein molecules outside the liposome were removed. With such a high calcein concentration, its fluorescence is self-quenched. If the lipid membrane is disrupted, calcein is released into the whole solution yielding fluorescence enhancement. After mixing calcein-loaded liposomes with nanoceria, we observed an immediate fluorescence quenching, suggesting that nanoceria adsorbed the free calcein molecules outside the liposome (note that some free calcein still exists in our system). Adding Triton X-100 to fully rupture the membrane however still failed to induce fluorescence 
enhancement and further quenching was observed (Figure 5a), which is also attributable to calcein adsorption by nanoceria. To confirm this, we added nanoceria to a free calcein solution and indeed we observed efficient fluorescence quenching (Figure 5b). Therefore, direct monitoring of fluorescence cannot be used here.

From our above studies, we know that nanoceria has a strong affinity to phosphate. We reason that phosphate might displace calcein from the nanoceria surface as schematically shown in Figure 5c. To confirm this, we added phosphate to the above control sample and indeed observed fluorescence increase (Figure 5b). With this in mind, we next added various concentrations of nanoceria to calcein-loaded DOPC liposomes at 5 min (Figure 5d). All the samples showed fluorescence quenching to the background level. At $25 \mathrm{~min}$, we added phosphate and observed a strong fluorescence enhancement. With more $\mathrm{CeO}_{2}$ added, higher fluorescence was observed after phosphate addition, and the recovered level was higher than the original level (e.g. fluorescence before $5 \mathrm{~min}$ ). This indicates the liposome leaked upon addition of $\mathrm{CeO}_{2}$ and the leaking process is $\mathrm{CeO}_{2}$ concentration dependent. Further adding Triton-X100 fully ruptured liposomes and released all the encapsulated calcein. 

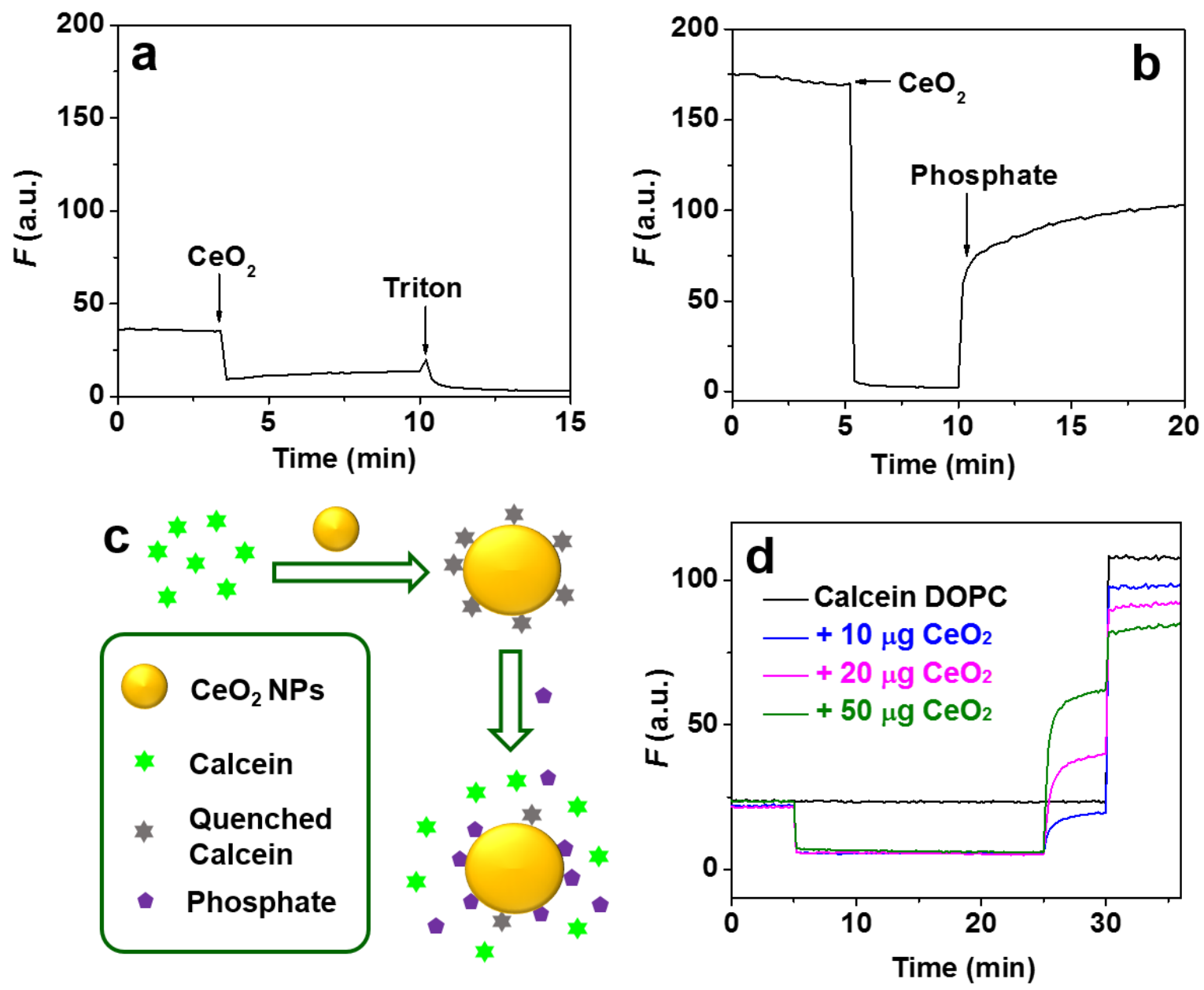

Figure 5. (a) Calcein-loaded DOPC leakage test by adding $\mathrm{CeO}_{2} \mathrm{NPs}$. Triton $\mathrm{X}-100$ was added to fully disrupt the liposomes. The quenching of fluorescence is due to calcein adsorption by $\mathrm{CeO}_{2}$. (b) Phosphate displacement of free calcein adsorbed on $\mathrm{CeO}_{2} \mathrm{NPs}$. (c) Schematic illustration of calcein fluorescence recovery by adding phosphate. (d) Leakage tests of calceinloaded DOPC liposome by adding $\mathrm{CeO}_{2}$ at $5 \mathrm{~min}$. At $25 \mathrm{~min}$, phosphate was added, and at 30 min, Triton X-100 was added. 
Cryo-TEM characterization. This is the first time that we observed DOPC liposome leakage when mixed with a non-silica and non-cationic oxide. ${ }^{46} \mathrm{At} \mathrm{pH} 7.6, \mathrm{CeO}_{2}$ is near charge neutral (slightly negatively charged), and thus the leakage is unlikely due to membrane damage by cationic nanomaterials. ${ }^{46,47}$ From the surface chemistry standpoint, $\mathrm{CeO}_{2}$ is more similar to $\mathrm{TiO}_{2}$ in terms of containing a hard Lewis acid metal favoring strong phosphate interaction, which is demonstrated in this work. Therefore, we want to understand whether this is due to fully ruptured liposomes or local membrane damages. For this purpose, TEM was used. Using the normal TEM, we observed that the distribution of $\mathrm{CeO}_{2}$ (Figure 6a) is quite different from that in the absence and presence of liposome (inset of Figure 1a). While we can see the $\mathrm{CeO}_{2}$ NPs distributed around a liposome shaped contour, we cannot resolve the liposomes. Using cryo-TEM, we indeed observed $\mathrm{CeO}_{2}$ adsorption and the liposome structure was still largely maintained, although deformation of liposomes from perfect spherical structure was also observed (Figure $6 b)$.

As such, the leakage must be due to local interaction between $\mathrm{CeO}_{2}$ and the liposomes. As a further control, we tested calcein-loaded DPPC liposomes, and $\mathrm{CeO}_{2} \mathrm{NPs}$ failed to leak them (Figure 6c). DPPC and DOPC have the same headgroup chemistry, and the only difference is that DPPC is in the gel phase at room temperature with a phase transition temperature $\left(T_{\mathrm{c}}\right)$ of $41^{\circ} \mathrm{C}$. On the other hand, DOPC has a $T_{\mathrm{c}}$ of $-20^{\circ} \mathrm{C}$ and is fluid at room temperature. Therefore, leakage of DOPC liposomes is likely to relate to the $T_{\mathrm{c}}$.

One possibility is that the adsorption is very strong, and it can raise the $T_{\mathrm{c}}$ of the lipid at the spot of adsorption. ${ }^{22}$ We observed such a phenomenon with gold nanoparticles. ${ }^{43,}{ }^{48}$ In that case, we attributed it to the strong van der Waals force between gold and liposome. Here, the $\mathrm{CeO}_{2}$ NPs were brought very close to the liposome surface by the lipid phosphate interaction. If 
this hypothesis is true, $\mathrm{CeO}_{2}$ NPs should increase the $T_{\mathrm{c}}$ of liposomes. Therefore, we used DSC to measure the DPPC liposomes (Figure 6d). Free DPPC has a $T_{\mathrm{c}}$ of $41{ }^{\circ} \mathrm{C}$ as expected. After adding a 1:1 mass ratio of $\mathrm{CeO}_{2} \mathrm{NPs}$, its $T_{\mathrm{c}}$ shifted to $42.5{ }^{\circ} \mathrm{C}$. Further increase the $\mathrm{CeO}_{2}$ concentration by 5 -fold raised the $T_{\mathrm{c}}$ to $43.2{ }^{\circ} \mathrm{C}$ with a significant peak broadening. We reason that at the spot of adsorption, the DOPC lipids underwent a fluid-to-gel phase transition, and calcein can leak during this transition period. Once adsorbed, the liposome becomes stable again. 22, 43, 48, 49 The DPPC liposome is already in the gel phase, and thus adding nanoceria would not induce the phase transition and thus no leakage took place.
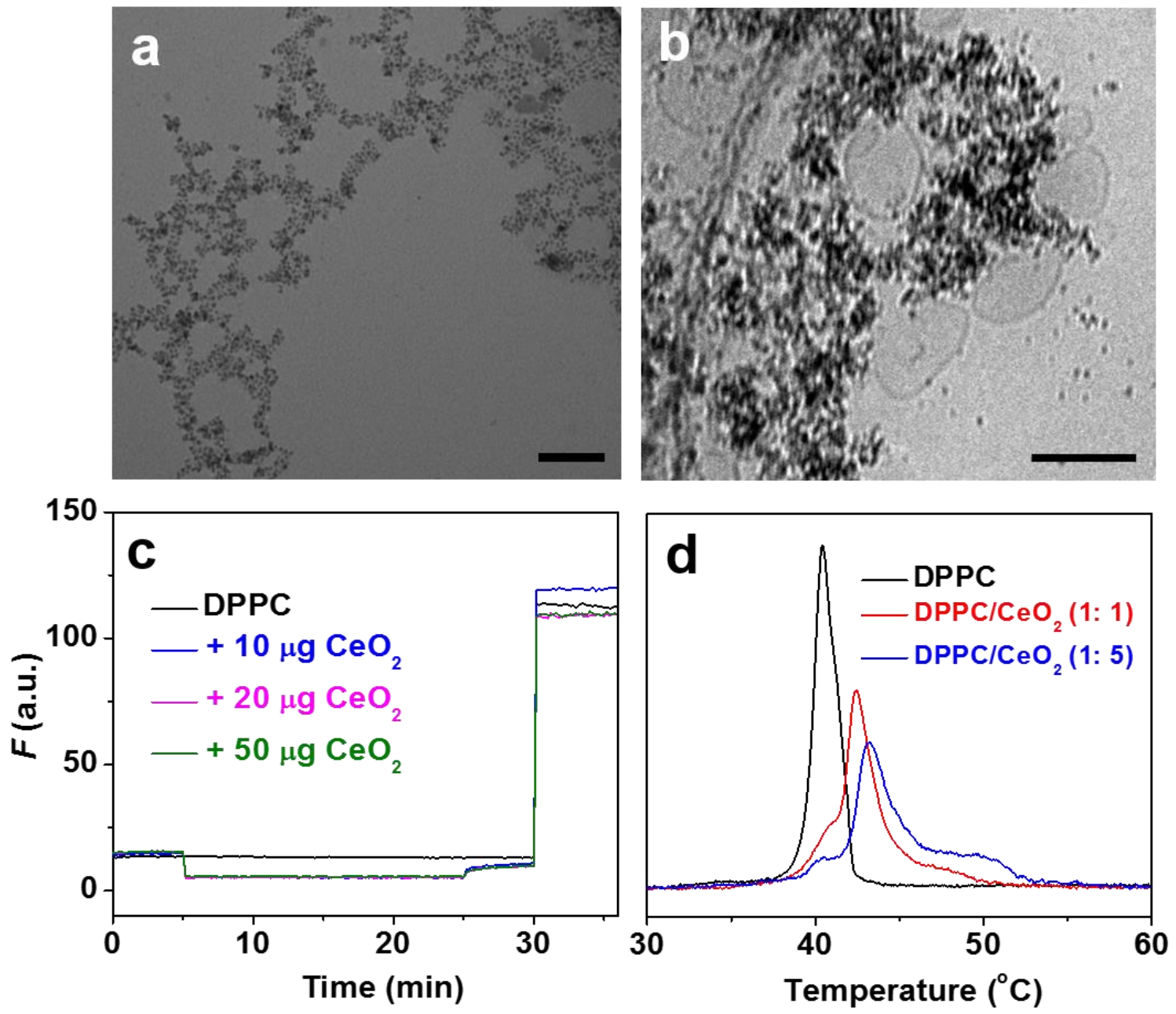
Figure 6. TEM image (a) and Cryo-TEM (b) of DOPC liposome mixed with $\mathrm{CeO}_{2} \mathrm{NPs}$ (scale bars $=100 \mathrm{~nm}$ ). (c) Calcein leakage tests of DPPC liposomes with $\mathrm{CeO}_{2}$ added at 5 min, phosphate added at $25 \mathrm{~min}$ and Triton X-100 added at $30 \mathrm{~min}$. The buffer was $25 \mathrm{mM}$ HEPES ( $\mathrm{pH}$ 7.6). The final fluorescence after adding phosphate was lower than the initial fluorescence regardless of $\mathrm{CeO}_{2}$ concentration, suggesting no leakage occurred. (d) DCS traces of DPPC liposomes as a function of $\mathrm{CeO}_{2}$ concentration. The ratio refers to the mass concentration of DPPC and $\mathrm{CeO}_{2}$.

While this is a model study performed in a reduced physical system, it still has interesting biological implications. For example, nanoceria alone cannot enter the membrane and it has to be internalized by cells by active transportation, likely via endocytosis. ${ }^{10,16}$ In the acidic endosome and lysosome, the surface charge of nanoceria changes from neutral to positive, and this is likely to have an influence on its membrane interactions. Nanoceria can strongly bind to the phosphate group in lipids and this is likely to be true for all the phospholipids. Such interaction can even change the lipid phase transition temperature and induce a transient membrane leakage.

\section{Conclusions}

In summary, the interaction between PC liposomes and $\mathrm{CeO}_{2} \mathrm{NPs}$ were systematically studied using a suite of techniques. We are interested in nanoceria due to its anti-oxidation activity widely tested in many cellular and animal studies in recent years. Two types of liposomes: DOPC and DPPC were included in this study. They have the same headgroup chemistry but different $T_{\mathrm{c}}$. The fluorescence quenching experiments indicated that $\mathrm{CeO}_{2} \mathrm{NPs}$ are adsorbed by 
DOPC at both $\mathrm{pH} 4$ and $\mathrm{pH}$ 7.6. The interaction between the phosphate in the lipid headgroup and $\mathrm{CeO}_{2}$ is mainly responsible for the adsorption. At $\mathrm{pH} 4, \mathrm{CeO}_{2} \mathrm{NPs}$ are positively charged, while at $\mathrm{pH}$ 7.6, they are nearly charge neutral. Such electrostatic factors showed a strong influence on the observed adsorption isotherms. When $\mathrm{CeO}_{2}$ is positively charged, the complexes can be re-stabilized with relatively higher amount of $\mathrm{CeO}_{2} \mathrm{NPs} \mathrm{CeO}_{2}$ could induce the leakage of DOPC. This is the first time that we observed that DOPC liposome leaked by a non-cationic metal oxide, and the leakage was attributed the $\mathrm{CeO}_{2}$ adsorption induced local fluid-to-gel phase transition. This work provides fundamental understandings of the interaction between lipid bilayers and $\mathrm{CeO}_{2} \mathrm{NPs}$ at the molecular level, which may offer insights into $\mathrm{CeO}_{2}$ interaction with cell membranes.

\section{ASSOCIATED CONTENT}

\section{Supporting Information}

The Supporting Information is available free of charge on the ACS Publications website at DOI:

UV-Vis spectra of $\mathrm{CeO}_{2}$ and $\mathrm{CeO}_{2} / \mathrm{DOPC}$ complexes at $\mathrm{pH} 4$ and $\mathrm{pH} 7.6$ (Figure $\mathrm{S} 1$ ), fluorescence adsorption of $\mathrm{Rh}-\mathrm{DOPC}$ with the addition of $\mathrm{CeO}_{2}$ and $\mathrm{NaCl}$ (Figure S2) and fluorescence spectra of Rh-DOPC before and after centrifugation at $\mathrm{pH} 7.6$ and $\mathrm{pH} 4$ (Figure S3).

\section{Author Information}

\section{Corresponding Author}

*Email: liujw@uwaterloo.ca. 


\section{Notes}

The authors declare no competing financial interest.

\section{Acknowledgement}

We thank Robert Harris at the University of Guelph for assistance during the cryo-TEM experiment and Biwu Liu for HRTEM. Funding for this work is from the Natural Sciences and Engineering Research Council of Canada (NSERC).

\section{References}

(1) Montini, T.; Melchionna, M.; Monai, M.; Fornasiero, P., Fundamentals and Catalytic Applications of $\mathrm{CeO}_{2}$-Based Materials. Chem. Rev. 2016, 116, 5987-6041.

(2) Xu, C.; Qu, X., Cerium Oxide Nanoparticle: A Remarkably Versatile Rare Earth Nanomaterial for Biological Applications. NPG Asia Mater 2014, 6, e90.

(3) Ujjain, S. K.; Das, A.; Srivastava, G.; Ahuja, P.; Roy, M.; Arya, A.; Bhargava, K.; Sethy, N.; Singh, S. K.; Sharma, R. K.; Das, M., Nanoceria Based Electrochemical Sensor for Hydrogen Peroxide Detection. Biointerphases 2014, 9, 031011.

(4) Celardo, I.; Pedersen, J. Z.; Traversa, E.; Ghibelli, L., Pharmacological Potential of Cerium Oxide Nanoparticles. Nanoscale 2011, 3, 1411-1420.

(5) Korsvik, C.; Patil, S.; Seal, S.; Self, W. T., Superoxide Dismutase Mimetic Properties Exhibited by Vacancy Engineered Ceria Nanoparticles. Chem. Commun. 2007, 10561058. 
(6) Dowding, J. M.; Das, S.; Kumar, A.; Dosani, T.; McCormack, R.; Gupta, A.; Sayle, T. X. T.; Sayle, D. C.; von Kalm, L.; Seal, S.; Self, W. T., Cellular Interaction and Toxicity Depend on Physicochemical Properties and Surface Modification of Redox-Active Nanomaterials. ACS Nano 2013, 7, 4855-4868.

(7) Chen, J.; Patil, S.; Seal, S.; McGinnis, J. F., Rare Earth Nanoparticles Prevent Retinal Degeneration Induced by Intracellular Peroxides. Nat Nano 2006, 1, 142-150.

(8) Lin, Y. H.; Ren, J. S.; Qu, X. G., Catalytically Active Nanomaterials: A Promising Candidate for Artificial Enzymes. Acc. Chem. Res. 2014, 47, 1097-1105.

(9) Walkey, C.; Das, S.; Seal, S.; Erlichman, J.; Heckman, K.; Ghibelli, L.; Traversa, E.; McGinnis, J. F.; Self, W. T., Catalytic Properties and Biomedical Applications of Cerium Oxide Nanoparticles. Environ. Sci. Nano 2015, 2, 33-53.

(10) Xia, T.; Kovochich, M.; Liong, M.; Mädler, L.; Gilbert, B.; Shi, H.; Yeh, J. I.; Zink, J. I.; Nel, A. E., Comparison of the Mechanism of Toxicity of Zinc Oxide and Cerium Oxide Nanoparticles Based on Dissolution and Oxidative Stress Properties. ACS Nano 2008, 2, 2121-2134.

(11) Hirst, S. M.; Karakoti, A. S.; Tyler, R. D.; Sriranganathan, N.; Seal, S.; Reilly, C. M., Anti-Inflammatory Properties of Cerium Oxide Nanoparticles. Small 2009, 5, 2848-2856.

(12) Lyu, G.-M.; Wang, Y.-J.; Huang, X.; Zhang, H.-Y.; Sun, L.-D.; Liu, Y.-J.; Yan, C.-H., Hydrophilic $\mathrm{CeO}_{2}$ Nanocubes Protect Pancreatic $\beta$-Cell Line Ins-1 from $\mathrm{H}_{2} \mathrm{O}_{2}$-Induced Oxidative Stress. Nanoscale 2016, 8, 7923-7932.

(13) Celardo, I.; De Nicola, M.; Mandoli, C.; Pedersen, J. Z.; Traversa, E.; Ghibelli, L., Ce ${ }^{3+}$ Ions Determine Redox-Dependent Anti-Apoptotic Effect of Cerium Oxide Nanoparticles. ACS Nano 2011, 5, 4537-4549. 
(14) Perez, J. M.; Asati, A.; Nath, S.; Kaittanis, C., Synthesis of Biocompatible DextranCoated Nanoceria with pH-Dependent Antioxidant Properties. Small 2008, 4, 552-556.

(15) Tarnuzzer, R. W.; Colon, J.; Patil, S.; Seal, S., Vacancy Engineered Ceria Nanostructures for Protection from Radiation-Induced Cellular Damage. Nano Lett. 2005, 5, 2573-2577.

(16) Ji, Z.; Wang, X.; Zhang, H.; Lin, S.; Meng, H.; Sun, B.; George, S.; Xia, T.; Nel, A. E.; Zink, J. I., Designed Synthesis of $\mathrm{CeO}_{2}$ Nanorods and Nanowires for Studying Toxicological Effects of High Aspect Ratio Nanomaterials. ACS Nano 2012, 6, 53665380.

(17) Kim, C. K.; Kim, T.; Choi, I.-Y.; Soh, M.; Kim, D.; Kim, Y.-J.; Jang, H.; Yang, H.-S.; Kim, J. Y.; Park, H.-K.; Park, S. P.; Park, S.; Yu, T.; Yoon, B.-W.; Lee, S.-H.; Hyeon, T., Ceria Nanoparticles That Can Protect against Ischemic Stroke. Angew. Chem., Int. Ed. 2012, 51, 11039-11043.

(18) Kumar, A.; Das, S.; Munusamy, P.; Self, W.; Baer, D. R.; Sayle, D. C.; Seal, S., Behavior of Nanoceria in Biologically-Relevant Environments. Environ. Sci. Nano 2014, 1, 516532.

(19) Nel, A. E.; Madler, L.; Velegol, D.; Xia, T.; Hoek, E. M. V.; Somasundaran, P.; Klaessig, F.; Castranova, V.; Thompson, M., Understanding Biophysicochemical Interactions at the Nano-Bio Interface. Nat. Mater. 2009, 8, 543-557.

(20) Verma, A.; Stellacci, F., Effect of Surface Properties on Nanoparticle-Cell Interactions. Small 2010, 6, 12-21.

(21) Liu, J., Interfacing Zwitterionic Liposomes with Inorganic Nanomaterials: Surface Forces, Membrane Integrity, and Applications. Langmuir 2016, 32, 4393-4404. 
(22) Wang, B.; Zhang, L. F.; Bae, S. C.; Granick, S., Nanoparticle-Induced Surface Reconstruction of Phospholipid Membranes. Proc. Natl. Acad. Sci. U.S.A. 2008, 105, 18171-18175.

(23) Gao, W.; Hu, C.-M. J.; Fang, R. H.; Zhang, L., Liposome-Like Nanostructures for Drug Delivery. J. Mater. Chem. B 2013, 1, 6569-6585.

(24) Tan, S.; Li, X.; Guo, Y.; Zhang, Z., Lipid-Enveloped Hybrid Nanoparticles for Drug Delivery. Nanoscale 2012, 5, 860-872.

(25) Rascol, E.; Devoisselle, J.-M.; Chopineau, J., The Relevance of Membrane Models to Understand Nanoparticles-Cell Membrane Interactions. Nanoscale 2016, 8, 4780-4798.

(26) Oliver, A. E.; Parikh, A. N., Templating Membrane Assembly, Structure, and Dynamics Using Engineered Interfaces. Biochimica Et Biophysica Acta-Biomembranes 2010, 1798, 839-850.

(27) Wang, F.; Liu, J., Liposome Supported Metal Oxide Nanoparticles: Interaction Mechanism, Light Controlled Content Release, and Intracellular Delivery. Small 2014, 10, 3927-3931.

(28) Wang, F.; Liu, J., A Stable Lipid/ $\mathrm{TiO}_{2}$ Interface with Headgroup-Inversed Phosphocholine and a Comparison with $\mathrm{SiO}_{2}$. J. Am. Chem. Soc. 2015, 137, 11736-11742.

(29) Reimhult, E.; Hook, F.; Kasemo, B., Intact Vesicle Adsorption and Supported Biomembrane Formation from Vesicles in Solution: Influence of Surface Chemistry, Vesicle Size, Temperature, and Osmotic Pressure Langmuir 2003, 19, 1681-1691.

(30) Ip, A. C. F.; Liu, B.; Huang, P.-J. J.; Liu, J., Oxidation Level-Dependent Zwitterionic Liposome Adsorption and Rupture by Graphene-Based Materials and Light-Induced Content Release. Small 2013, 9, 1030-1035. 
(31) Cremer, P. S.; Boxer, S. G., Formation and Spreading of Lipid Bilayers on Planar Glass Supports. J. Phys. Chem. B 1999, 103, 2554-2559.

(32) Mornet, S.; Lambert, O.; Duguet, E.; Brisson, A., The Formation of Supported Lipid Bilayers on Silica Nanoparticles Revealed by Cryoelectron Microscopy. Nano Lett. 2005, $5,281-285$.

(33) Richter, R. P.; Berat, R.; Brisson, A. R., Formation of Solid-Supported Lipid Bilayers: An Integrated View. Langmuir 2006, 22, 3497-3505.

(34) Cho, N.-J.; Jackman, J. A.; Liu, M.; Frank, C. W., pH-Driven Assembly of Various Supported Lipid Platforms: A Comparative Study on Silicon Oxide and Titanium Oxide. Langmuir 2011, 27, 3739-3748.

(35) Jackman, J. A.; Zan, G. H.; Zhao, Z.; Cho, N.-J., Contribution of the Hydration Force to Vesicle Adhesion on Titanium Oxide. Langmuir 2014, 30, 5368-5372.

(36) Michel, R.; Kesselman, E.; Plostica, T.; Danino, D.; Gradzielski, M., Internalization of Silica Nanoparticles into Fluid Liposomes: Formation of Interesting Hybrid Colloids. Angew. Chem. Int. Ed. 2014, 53, 12441-12445.

(37) Sehgal, A.; Lalatonne, Y.; Berret, J. F.; Morvan, M., Precipitation-Redispersion of Cerium Oxide Nanoparticles with Poly(Acrylic Acid): Toward Stable Dispersions. Langmuir 2005, 21, 9359-9364.

(38) Qi, L.; Sehgal, A.; Castaing, J.-C.; Chapel, J.-P.; Fresnais, J. r. m.; Berret, J.-F. o.; Cousin, F., Redispersible Hybrid Nanopowders: Cerium Oxide Nanoparticle Complexes with Phosphonated-Peg Oligomers. ACS Nano 2008, 2, 879-888. 
(39) Asati, A.; Santra, S.; Kaittanis, C.; Nath, S.; Perez, J. M., Oxidase-Like Activity of Polymer-Coated Cerium Oxide Nanoparticles. Angew. Chem., Int. Ed. 2009, 48, 23082312.

(40) Pautler, R.; Kelly, E. Y.; Huang, P.-J. J.; Cao, J.; Liu, B.; Liu, J., Attaching DNA to Nanoceria: Regulating Oxidase Activity and Fluorescence Quenching. ACS Appl. Mater. Inter. 2013, 5, 6820-6825.

(41) Mousseau, F.; Le Borgne, R.; Seyrek, E.; Berret, J. F., Biophysicochemical Interaction of a Clinical Pulmonary Surfactant with Nanoalumina. Langmuir 2015, 31, 7346-7354.

(42) Wang, F.; Liu, J., Nanodiamond Decorated Liposomes as Highly Biocompatible Delivery Vehicles and a Comparison with Carbon Nanotubes and Graphene Oxide. Nanoscale 2013, 5, 12375-12382.

(43) Wang, F.; Curry, D. E.; Liu, J., Driving Adsorbed Gold Nanoparticle Assembly by Merging Lipid Gel/Fluid Interfaces. Langmuir 2015, 31, 13271-13274.

(44) McCormack, R. N.; Mendez, P.; Barkam, S.; Neal, C. J.; Das, S.; Seal, S., Inhibition of Nanoceria's Catalytic Activity Due to $\mathrm{Ce}^{3+}$ Site-Specific Interaction with Phosphate Ions. J. Phys. Chem. C 2014, 118, 18992-19006.

(45) Liu, B.; Sun, Z.; Huang, P.-J. J.; Liu, J., Hydrogen Peroxide Displacing DNA from Nanoceria: Mechanism and Detection of Glucose in Serum. J. Am. Chem. Soc. 2015, 137, 1290-1295.

(46) Wang, F.; Zhang, X.; Liu, Y.; Lin, Z. Y.; Liu, B.; Liu, J., Profiling Metal Oxides with Lipids: Magnetic Liposomal Nanoparticles Displaying DNA and Proteins. Angew. Chem., Int. Ed. 2016, 55, 12063-12067. 
(47) Leroueil, P. R.; Berry, S. A.; Duthie, K.; Han, G.; Rotello, V. M.; McNerny, D. Q.; Baker, J. R.; Orr, B. G.; Banaszak Holl, M. B., Wide Varieties of Cationic Nanoparticles Induce Defects in Supported Lipid Bilayers. Nano Lett. 2008, 8, 420-424.

(48) Wang, F.; Liu, J., Self-Healable and Reversible Liposome Leakage by Citrate-Capped Gold Nanoparticles: Probing the Initial Adsorption/Desorption Induced Lipid Phase Transition. Nanoscale 2015, 7, 15599-15604.

(49) Zhang, L. F.; Granick, S., How to Stabilize Phospholipid Liposomes (Using Nanoparticles). Nano Lett. 2006, 6, 694-698. 